\title{
X-Ray Determination of Retained Austenite in Steel Using ASTM E975
}

\author{
Dennis W. Hetzner
}

The Timken Company, Box 6930, Canton, Ohio 44706

The origins of ASTM date back to the end of the $19^{\text {th }}$ century. At this time two of the largest industries in America were the railroads and the steel industry. While the railroads linked the nation, the steel purchased from one mill for a particular application could have greatly different properties than a similar alloy purchased from another mill. Establishing voluntary, consensus, conformance standards in the steel industry was one of the driving forces for the creation of ASTM. With this in mind, it seems obvious that the first ASTM committee to be formed was A01, Steel. As standards for steel alloys were being developed, the next logical progression was the development of standard methodologies to test materials; hence, committee E01 on test methods was formed. In 1916 committee E04 was spun off from committee E01. While the first focus of E04 was to develop a set of standard magnifications to use for evaluating steel microstructures, with time the scope became much broader. The current name "On Metallography" was adopted in 1921. Today ASTM International has over 30,000 members from more than 100 countries, and is responsible for over 11,000 standards. Committee E04 is currently responsible for 36 standards concerning metallography and similarly related topics. Standard E975 on the X-ray determination of retained austenite is one of the standards in Committee E04's charge.

Retained austenite is found in the microstructure of heat-treated, low-alloy, high-strength steels having carbon contents greater than $0.40 \%$ by weight. Depending upon the particular application, the transformation of retained to martensite can cause problems in some mechanical systems. This is because the transformation of austenite to martensite is accompanied by a volume increase of $4 \%$. Often, the presence or amount of retained austenite in the steel can not be assessed by microstructural observations. ASTM practice E975 covers the determination of retained austenite in steel specimens using the integrated intensities of $\mathrm{x}$-ray diffraction peaks. The permissible sources of radiation are chromium $\mathrm{K}_{\alpha}$ and molybdenum $\mathrm{K}_{\alpha}$. The practice assumes that the crystallographic orientation of both the austenite and martensite is random and that there is at least $1 \%$ retained austenite in the steel.

Austenite and martensite are allotropic forms of iron. Thus, quantitative analysis of the system is easier to perform than for multiphase systems composed of different species. The integrated x-ray diffraction intensity of a single peak is dependent upon numerous physical properties of the diffracting crystals and other properties that are related to the interactions and geometry of the x-ray beam impinging on the crystal [1]. The intensity equation can be expressed as:

$$
\mathbf{I}_{\alpha}=\frac{\mathbf{K} \mathbf{R}_{\alpha} \mathbf{V}_{\alpha}}{2 \mu} \quad \text { where } \quad \mathbf{R}=\left(\frac{1}{\mathbf{v}^{2}}\right)\left[|\mathbf{F}|^{2} \mathbf{p}\left(\frac{1+\cos ^{2} 2 \theta}{\sin ^{2} \theta \cos \theta}\right)\right]\left(\mathbf{e}^{-2 M}\right)
$$

The constant $\mathrm{K}$ is composed of various physical properties of the material. The terms in the $\mathrm{R}$ factor involve the unit cell volume, structure factor, crystallographic multiplicity factor, Lorentz polarization factor and the temperature factor. The amount of retained austenite in a specimen is 
related to the $\mathrm{R}$ factors and the measured integrated intensities of the austenite and martensite peaks by the following equation [2]:

$$
\mathbf{v}_{\gamma}=\frac{\frac{1}{q} \sum_{j=1}^{q} \frac{I_{\gamma} j}{R_{\gamma} j}}{\frac{1}{p} \sum_{i=1}^{p} \frac{I_{\alpha} i}{R_{\alpha} i}+\frac{1}{q} \sum_{j=1}^{q} \frac{I_{\gamma} j}{R_{\gamma} j}}
$$

where $\gamma$ represents the austenite phase, $\alpha$ represents the ferrite or martensite phase, and $\mathrm{p}$ and $\mathrm{q}$ are the number of martensite and austenite peaks used for the analysis.

While this relationship appears to be simple and straightforward, numerous factors can lead to problems in accurately determining the true volume fraction of retained austenite. Proper specimen preparation is a major factor that needs to be considered. The standards used to assess the accuracy of the x-ray systems are somewhat different than ordinary heat treated steels. The standards are generally made of two different types of stainless steels. The peaks of the standards are much narrower than the peaks often encountered in heat treated steels, Figure 1. The broad peak widths of steel specimens can result in under measuring the area of the martensite (211) plane, and thus result in an over estimate in the amount of retained austenite. Unfortunately, some of the NBS standards for retained austenite contain preferred orientation. This leads to problems in verifying the accuracy of the measuring system. These issues and several others will be considered in the presentation.

\section{References}

[1] Cullity, B. D., Elements of X-Ray Diffraction, Addison-Wesley, Reading, MA, 1967.

[2] ASTM E975-00, Standard Practice for X-Ray Determination of Retained Austenite in Steel with Near Random Crystallographic Orientation, American Society for Testing and Materials International, Volume 03.01, W. Conshohocken, PA, 2003.

Figure 1. The austenite (220) peak and the martensite (211) peak, $\mathrm{Cr}$ radiation. The black pattern with narrow peaks is from a NIST $30 \%$ retained austenite standard; the red pattern is from carburized 4320 steel.

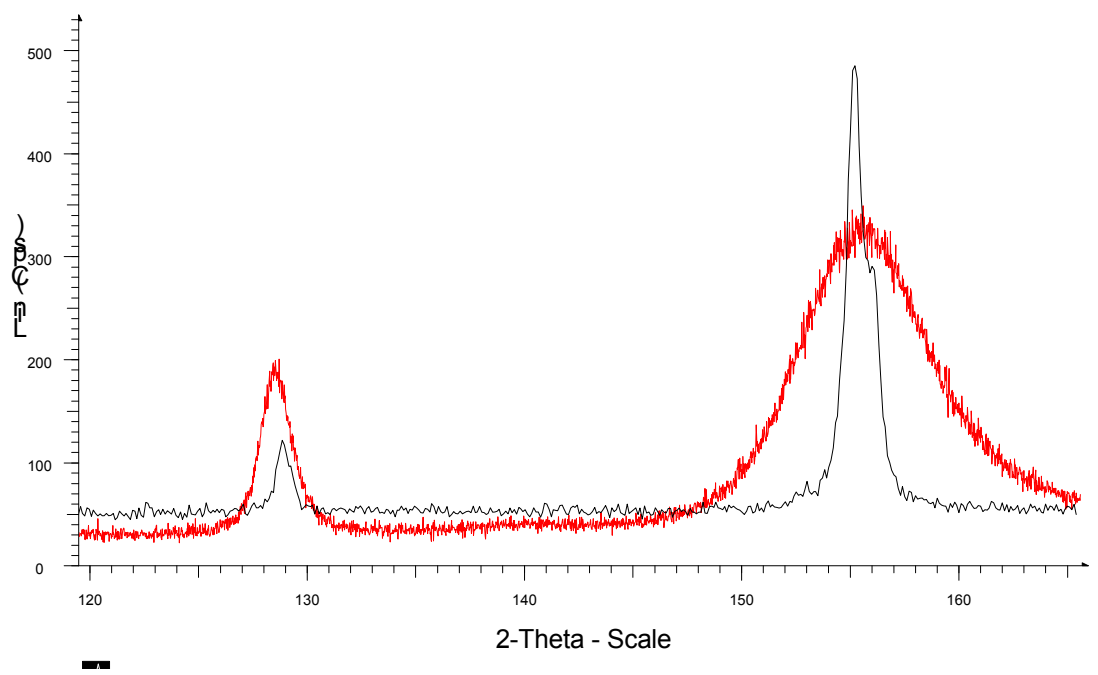

